\title{
PERAMALAN TINGKAT PENGHUNIAN KAMAR DENGAN MEMANFAATKAN DATA GOOGLE TRENDS DI PROVINSI BANTEN
}

\author{
Muhammad Fajar ${ }^{1}$, Teuku M. Madinah ${ }^{2}$, Hendro Prayitno ${ }^{3}$ \\ ${ }^{1}$ Badan Pusat Statistik Provinsi Banten \\ ${ }^{1}$ mfajar@bps.go.id, ${ }^{2}$ teuku@bps.go.id, ${ }^{3}$ hendrop@bps.go.id
}

\begin{abstract}
The purpose of this paper is to forecast the room occupancy rate (ROR) of star hotels by utilizing Google Trends data, in addition to historical ROR data. The data used is the ROR (\%) which comes from the Badan Pusat Statistik-Statistics Indonesia and the Google Trends query index using the search word "hotel". The method used is the ARIMAX model. The results of this study indicate that the ARIMAX model has excellent forecasting capabilities. This is shown by the MAPE value which reached $6.541 \%$, which means the added value of the hotel sector in the first quarter of 2021 is not expected to increase significantly.
\end{abstract}

Keywords: hotel, Google Trends, TPK, ARIMAX.

\begin{abstract}
Abstrak
Tujuan paper ini untuk meprediksi tingkat penghunian kamar (TPK) pada hotel berbintang dengan memanfaatkan data Google Trends, selain historis data TPK. Data yang digunakan adalah TPK (\%) yang bersumber dari Badan Pusat Statistik dan indeks query Google Trends dengan menggunakan kata pencarian "hotel". Adapun metode yang digunakan adalah ARIMAX. Hasil penelitian ini menunjukkan bahwa model ARIMAX memiliki kemampuan peramalan yang sangat baik. Ini ditunjukkan oleh nilai MAPE yang mencapai $6.541 \%$, yang berarti nilai tambah dari sektor perhotelan pada kuartal I 2021 diperkirakan masih belum meningkat signifikan.
\end{abstract}

Kata kunci: hotel, Google Trends, TPK, ARIMAX.

Received: May 8, 2021 / Accepted: August 8, 2021 / Published Online: August 30, 2021 


\section{PENDAHULUAN}

Provinsi Banten merupakan provinsi yang letaknya dekat dengan ibukota DKI Jakarta, memiliki kekayaan alam dan budaya yang dijadikan objek wisata, seperti pantai Anyer, pantai Sawarna, Tanjung Lesung, pantai Bagedur, Kampung Baduy, dan lain sebagainya. Keberadaan objek wisata tersebut dapat meningkatkan perekonomian lokal, dimana terjadi transaksi ekonomi dari warga luar Banten atau turis asing dengan warga setempat. Namun, pada tahun 2020 sampai kini terjadi pandemi COVID-19 yang menyebar ke seluruh wilayah Indonesia, termasuk Banten.

Dalam rangka pengendalian penyebaran COVID-19, pemerintah menerapkan PSBB dan PPKM Mikro, yang berimplikasi pada terbatasnya mobilitas manusia dan menurunnya kegiatan perekonomian. Ini tercermin pada laju pertumbuhan ekonomi Banten (year on year) pada tahun 2020 kuartal II, III, IV bernilai negatif (lihat gambar 1), yaitu $-7.27 \%,-5.32 \%$, dan $-3.92 \%$, artinya perekonomian Banten mengalami kontraksi dibandingkan setahun sebelumnya pada kuartal yang bersesuaian, dan jika dilihat dari besarannya sudah menunjukkan pemulihan walaupun masih dalam kondisi kontraksi.

Sementara itu, untuk mengetahui dampak COVID-19 terhadap sektor pariwisata Banten, salah satunya dapat diindikasikan dari indikator tingkat penghunian kamar pada hotel bintang. Berdasarkan pergerakan data TPK hotel bintang, terlihat pada bulan Mei dan Juni 2020 terjadi penurunan signifikan akibat dampak COVID-19, kemudian meningkat ketika menuju dan memasuki tahun 2021. Ini berarti sektor perhotelan mengalami guncangan, kemudian menunjukkan pemulihan pada kuartal terakhir 2020 dan awal 2021, yang menunjukkan tamu-tamu hotel sudah semakin banyak datang menginap pada hotel bintang yang ada di Banten, sehingga ini secara tidak langsung dapat dikatakan sektor pariwisata mengalami hal serupa dengan kondisi sektor perhotelan.

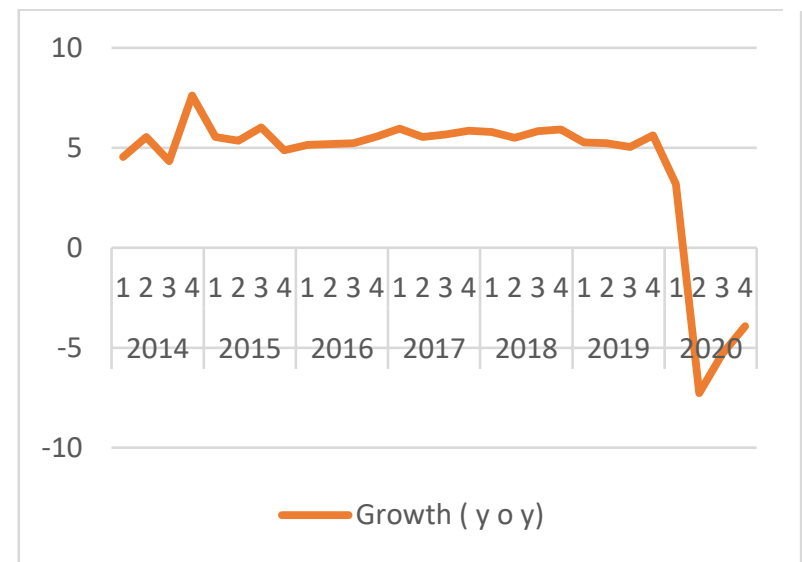

(a)

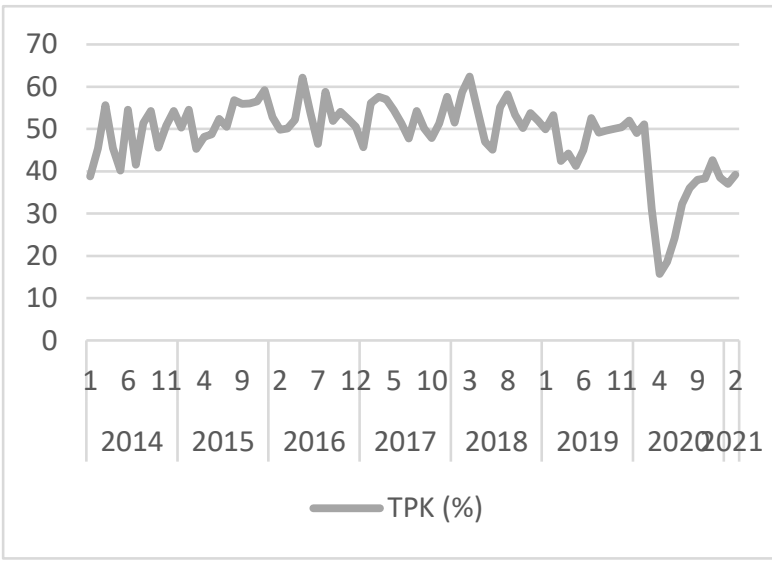

(b)

Gambar 1, (a) laju pertumbuhan ekonomi (year on year, \%) Banten, periode 2014Q1 - 2020Q4, (b) laju pergerakan TPK (\%), periode Januari 2014 - Maret 2021.

Oleh karena itu, untuk mengetahui kondisi sektor perhotelan di masa depan dibutuhkan data terkini yang harus tersedia, namun indikator tingkat penghunian kamar (TPK) pada bulan berjalan yang dikeluarkan BPS dirilis pada bulan berikutnya, sehingga ada hambatan untuk dapat memperkirakan kondisi sektor perhotelan. Solusi atas masalah ini dapat diatasi dengan menggunakan suatu leading 
indicator yang dapat digunakan sebagai proxy kondisi terkini. Penulis mengajukan data google trend sebagai leading indicator terkini yang digunakan sebagai eksogen dalam model ARIMAX, untuk mendapatkan prediksi TPK pada bulan berjalan dan yang akan datang, sehingga kondisi sektor perhotelan terkini dapat diketahui karena TPK salah satu proxy output yang dihasilkan sektor perhotelan. Adapun model yang menggunakan data google trends sebagai variabel eksogen menunjukkan hasil prediksi yang relatif baik (Anggraeni dan Aristiani, 2016; Fajar et al., 2020; Huang et al., 2019; Woo dan Owen, 2019).

\section{METODE PENELITIAN}

\section{Sumber Data}

Data yang digunakan dalam penelitian ini adalah tingkat penghunian kamar (TPK) pada hotel bintang $\left(x_{t}\right)$ di Provinsi Banten dalam level bulanan selama periode Januari 2014 - Maret 2021. Data Google Trends dengan menggunakan istilah "hotel" dalam meminta query data $\left(z_{t}\right)$, dengan periode data Januari 2014 - Maret 2021. Data yang digunakan sebagai data training adalah data pada periode Januari 2014 - Desember 2020. Selanjutnya, dalam penelitian akan dilakukan peramalan tingkat penghunian kamar untuk periode Januari - Maret 2021 sebagai data testing.

\section{Metode Analisis}

ARIMAX

Secara umum model ARIMA $(p, d, q)$ untuk suatu time series $x_{t}, t=1, \ldots, T$ (dalam hal ini tingkat pengangguran terbuka) adalah:

$$
\Phi_{P} B^{S} \phi_{p}(B)(1-B)^{d}\left(1-B^{S}\right)^{D} x_{t}=\mu+\theta_{q}(B) \Theta_{Q}\left(B^{S}\right) \varepsilon_{t}
$$

dengan:

$\begin{array}{ll}\mu & : \text { intersep } \\ B & : \text { Lag operator } \\ p, q & : \text { order autoregressive non musiman dan order moving average non musiman. } \\ P, Q & : \text { order autoregressive musiman dan order moving average musiman. } \\ d & : \text { order differencing non musiman. } \\ D & : \text { order differencing musiman. } \\ S & : \text { periode musiman, untuk data bulanan }(S=12), \text { data kuartal }(S=4) . \\ \phi_{p}(B) & : \text { komponen autoregressive non musiman. } \\ \Phi_{P} B^{S} & : \text { komponen autoregressive musiman. } \\ \theta_{q}(B) & : \text { komponen moving average non musiman. } \\ \Theta_{Q}\left(B^{S}\right) & : \text { komponen moving average musiman. } \\ (1-B)^{d} & : \text { differencing non musiman. } \\ \left(1-B^{S}\right)^{D} & : \text { differencing musiman. } \\ \varepsilon_{t} & : \text { error term. }\end{array}$


Estimasi parameter model ARIMA dapat dilakukan dengan metode maximum likelihood. Dalam penentuan order ARIMA menggunakan BIC (Bayesian Information Criteria) minimum. BIC dirumuskan:

$$
\begin{aligned}
& B I C=-2 \times \frac{\log (\text { maximum likelihood pada model ARIMAX) }}{T} \\
& +\frac{\text { (banyaknya parameter dalam model) } \times \log (T)}{T}
\end{aligned}
$$

Pada unsur variabel eksogen $z_{t}$ (indeks query Google Trends dengan kata pencarian "hotel") dimasukkan ke persamaan (1) sehingga menjadi:

$$
\Phi_{P} B^{S} \phi_{p}(B)(1-B)^{d}\left(1-B^{S}\right)^{D} x_{t}=\mu+(1-B)^{\delta} z_{t}+\theta_{q}(B) \Theta_{Q}\left(B^{S}\right) \varepsilon_{t}
$$

Dengan

$(1-B)^{\delta} \quad$ : differencing non musiman untuk variabel eksogen

$\delta \quad$ :order difference untuk variabel eksogen

Persamaan (2) adalah ARIMAX (Bierens, 1987), model (2) diestimasi dengan metode maximum likelihood berdasarkan optimasi algoritma BFGS.

\section{Akurasi Peramalan}

Akurasi peramalan pada data testingdalam penelitian ini menggunakan MAPE (Mean Absolute Percentage Error) yang dirumuskan sebagai berikut:

$$
M A P E=\frac{1}{v-T} \sum_{t=T+1}^{v}\left|\frac{F_{t}-A_{t}}{A_{t}} \times 100 \%\right|
$$

dengan $F_{t}$ adalah nilai hasil peramalan ke-t, dan $A_{t}$ adalah nilai aktual ke-t. Kriteria MAPE (Chang et al., 2007): (1) jika nilai MAPE < 10\%, maka kemampuan peramalan suatu metode/model adalah sangat baik, (2) jika nilai MAPE berada pada 10\% - 20\%, maka kemampuan peramalan suatu metode/model adalah baik, (3) jika nilai MAPE berada pada 20\% - 50\%, maka kemampuan peramalan suatu metode/model adalah cukup baik, dan (4) jika nilai MAPE > 50\%, maka kemampuan peramalan suatu metode/model adalah buruk.

\section{HASIL DAN PEMBAHASAN}

Pada gambar 2 disajikan secara visual, pergerakan data indeks query Google Trends dan TPK (\%) selama periode observasi menunjukkan koherensi yang sama, terbukti ketika pada tahun 2020, baik TPK maupun indeks query Google Trend menunjukkan palung pada kuartal II dan III tahun 2020 yang menunjukkan bahwa shock akibat pandemi COVID-19 yang membuat lesu output pada sektor perhotelan. Namun, pada kuartal IV 2020 dan kuartal I 2021 terjadi pola meningkat pada kedua data tersebut yang mengindikasikan adanya perbaikan kondisi sektor perhotelan, dimana terjadi peningkatan jumlah tamu yang menginap pada periode tersebut dibandingkan periode sebelumnya. Berdasarkan tabel 1, diperoleh informasi bahwa data TPK dan indeks query google trend telah stasioner pada data level, sehingga kedua data tersebut langsung digunakan untuk estimasi model ARIMAX tanpa perlu transformasi difference terlebih dahulu. 
Jurnal Lebesgue : Jurnal Ilmiah Pendidikan Matematika, Matematika dan Statistika

Muhammad Fajar, Teuku M. Madinah, Hendro Prayitno

Volume 02, No. 2, Agustus, 2021 hal. 226 - 232

DOI Artikel: 10.46306/lb.v2i2.63

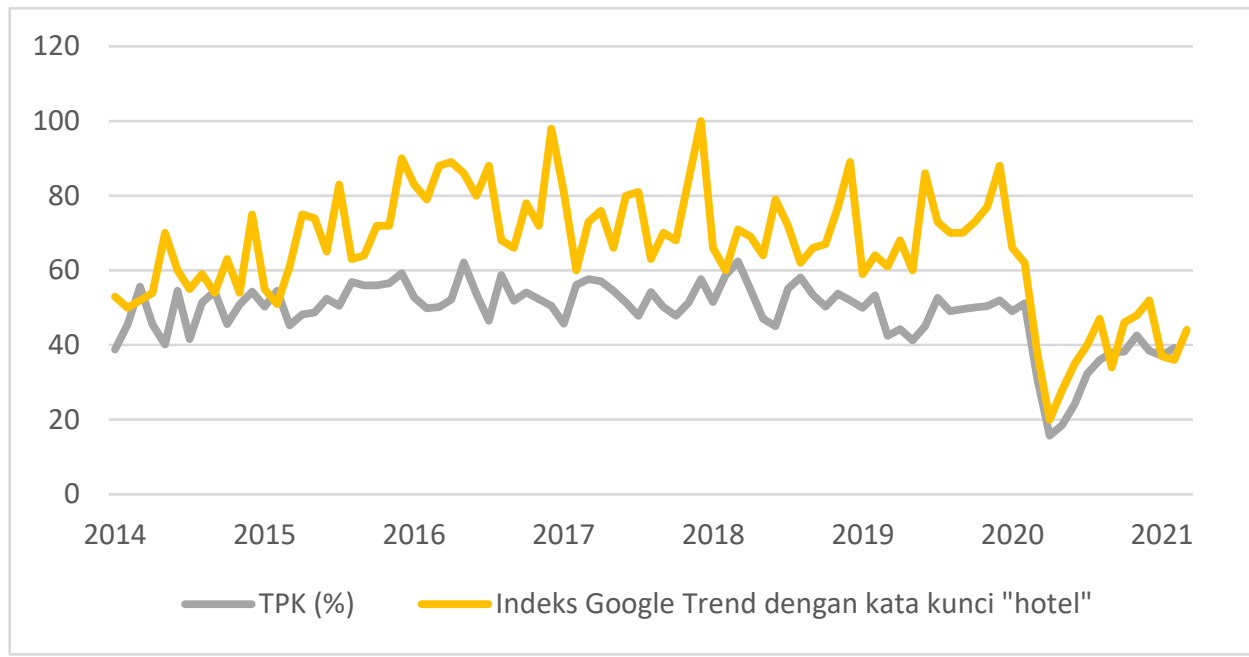

Gambar 2. Pergerakan Google Trend "hotel" dan tingkat penghunian kamar (TPK) di Provinsi Banten pada periode Januari 2014 - Maret 2021

Pada gambar 2 disajikan secara visual, pergerakan data indeks query Google Trends dan TPK (\%) selama periode observasi menunjukkan koherensi yang sama, terbukti ketika pada tahun 2020, baik TPK maupun indeks query Google Trend menunjukkan palung pada kuartal II dan III tahun 2020 yang menunjukkan bahwa shock akibat pandemi COVID-19 yang membuat lesu output pada sektor perhotelan. Namun, pada kuartal IV 2020 dan kuartal I 2021 terjadi pola meningkat pada kedua data tersebut yang mengindikasikan adanya perbaikan kondisi sektor perhotelan, dimana terjadi peningkatan jumlah tamu yang menginap pada periode tersebut dibandingkan periode sebelumnya. Berdasarkan tabel 1, diperoleh informasi bahwa data TPK dan indeks query google trend telah stasioner pada data level, sehingga kedua data tersebut langsung digunakan untuk estimasi model ARIMAX tanpa perlu transformasi difference terlebih dahulu.

Tabel 1. Hasil pengujian Phillip-Peron pada variabel tingkat penghunian kamar dan indeks query Google Trends (dengan menggunakan kata pencarian "hotel")

\begin{tabular}{|l|r|r|}
\hline & \multicolumn{1}{|c|}{ TPK } & \multicolumn{1}{|c|}{ Indeks query Google Trends } \\
\hline Data level & $(-4.293)$ & $(-3.901)$ \\
& {$[0.005]$} & {$[0.016]$} \\
\hline First Difference & $(-12.107)$ & $(-16.601)$ \\
& {$[0.000]$} & {$[0.000]$} \\
\hline
\end{tabular}

Selanjutnya. penentuan model terbaik ARIMAX didasarkan oleh Bayesian Information Criterion menggunakan selection model dari rentang order non seasonal AR 0 - 5, order seasonal AR: $0-5$, order non seasonal MA: $0-5$, order seasonal MA: $0-5$, order difference: 0 , dan order seasonal difference: 0. Model terbaik ARIMAX yang terpilih berdasarkan nilai AIC minimum adalah ARIMAX $(1,0,0)(1,0,0)(12)$. Ini berarti model ARIMAX tersebut memiliki spesifikasi order non seasonal AR adalah satu, dan order seasonal AR adalah satu. 
Jurnal Lebesgue : Jurnal Ilmiah Pendidikan Matematika, Matematika dan Statistika

Muhammad Fajar, Teuku M. Madinah, Hendro Prayitno

Volume 02, No. 2, Agustus, 2021 hal. 226 - 232

DOI Artikel: 10.46306/lb.v2i2.63

Tabel 2: Hasil Estimasi ARIMAX

\begin{tabular}{|c|c|c|c|r|}
\hline Coefficient & Value & Std. Error & Z-stat & $p$-value \\
\hline$\mu$ & 32.007 & 5.256 & 6.090 & $<0,0001$ \\
\hline$\phi_{1}$ & 0.520 & 0.124 & 4.192 & $<0,0001$ \\
\hline$\Phi_{1}$ & 0.473 & 0.115 & 4.107 & $<0,0001$ \\
\hline$z_{t}$ & 0.239 & 0.077 & 3.093 & 0,0020 \\
\hline R-squared & & 0.618 & BIC & 542.071 \\
\hline Log-likelihood & -259.959 & Chi-square stat. for normality & 1.380 \\
\hline p-value of Chi-square stat for normality & 0.502 & & \\
\hline
\end{tabular}

Berdasarkan hasil estimasi yang disajikan pada tabel 2, diperoleh informasi: (1) bahwa koefisien autoregressive (AR) baik seasonal dan non seasonal masing-masing adalah 0.520 dan 0.473 , yang siginifikan pada level alpha 5\%. Artinya, data TPK satu bulan sebelumnya berpengaruh pada satu bulan berjalan, baik secara data aktualnya maupun komponen musimannya, (2) indeks query google trend yang merupakan variabel eksogen, signifikan mempengaruhi TPK, (3) model ARIMAX $(1,0,0)$ $(1,0,0)(12)$ cukup mampu menjelaskan pergerakan data TPK sebesar $61.80 \%$.

Tabel 3. Hasil peramalan TPK dengan model ARIMAX

\begin{tabular}{|r|r|r|r|r|r|}
\hline Periode & $\begin{array}{c}\text { Indeks Query } \\
\text { Google Trends }\end{array}$ & TPK Aktual & $\begin{array}{c}\text { TPK } \\
\text { Forecasted } \\
\text { Forecasted } \\
\text { Lower }\end{array}$ & $\begin{array}{c}\text { TPK } \\
\text { Forecasted } \\
\text { Upper }\end{array}$ \\
\hline Januari 2021 & 37 & $37.06 \%$ & $38.63 \%$ & $28.37 \%$ & $48.90 \%$ \\
\hline Februari 2021 & 36 & $39.19 \%$ & $41.18 \%$ & $29.61 \%$ & $52.76 \%$ \\
\hline Maret 2021 & 44 & $41.30 \%$ & $37.05 \%$ & $25.15 \%$ & $48.95 \%$ \\
\hline \multicolumn{7}{|r|}{} & & MAPE & $6.541 \%$ \\
\hline
\end{tabular}

Berikut hasil peramalan TPK oleh ARIMAX untuk periode Januari - Maret 2021 tersaji pada tabel 2. Hasil peramalan model ARIMAX menunjukkan bahwa selama periode Januari - Juni 2020 menunjukkan adanya perlambatan. Ini mengindikasikan bahwa nilai tambah dari sektor perhotelan (terutama pada hotel bintang) pada kuartal I 2021 diperkirakan masih belum meningkat signifikan, yang dapat disebabkan oleh adanya PSBB (Pembatasan Sosial Berskala Besar) atau PPKM (Pemberlakuan Pembatasan Kegiatan Masyarakat Skala Mikro) sebagai upaya pengendalian penyebaran COVID-19 dan penundaan konsumsi untuk rekreasi (atau kebutuhan tertier) masyarakat sebagai antisipasi prospek ekonomi di masa depan yang masih belum pulih.

Dari sisi akurasi peramalan, model ARIMA menghasilkan MAPE terhadap data training sebesar $6.541 \%$. Ini berarti kemampuan peramalan model ARIMAX adalah sangat baik, namun yang perlu menjadi perhatian bahwa pemilihan variabel eksogen yang juga mengakomodir shock yang bersesuaian dengan variabel respon memegang kunci penting dalam akurasi peramalan di model tersebut. 
Jurnal Lebesgue : Jurnal Ilmiah Pendidikan Matematika, Matematika dan Statistika

Muhammad Fajar, Teuku M. Madinah, Hendro Prayitno

Volume 02, No. 2, Agustus, 2021 hal. 226 - 232

DOI Artikel: 10.46306/lb.v2i2.63

\section{KESIMPULAN}

Berdasarkan hasil pembahasan dapat ditarik kesimpulan bahwa model ARIMAX memiliki kemampuan peramalan yang sangat baik. Ini ditunjukkan oleh nilai MAPE yang mencapai $6.541 \%$. Model ini memprediksi bahwa nilai tambah dari sektor perhotelan pada kuartal I 2021 masih belum meningkat signifikan. yang dapat disebabkan oleh adanya PSBB atau PPKM guna pengendalian penyebaran COVID-19 dan penundaan konsumsi untuk rekreasi (atau kebutuhan tertier) masyarakat.

\section{DAFTAR PUSTAKA}

Anggraeni, W., Aristiani, L. 2016. Using Google Trend data in forecasting number of dengue fever cases with ARIMAX method case study: Surabaya, Indonesia. International Conference on Information \& Communication Technology and Systems (ICTS), pp. 114-118, DOI: 10.1109/ICTS.2016.7910283.

Bierens, H.J. 1987. ARMAX model specification testing, with an apllication to unemployment in the Netherlands. Journal of Econometrics, 35 (1), pp. 161-190. DOI: https://doi.org/10.1016/03044076(87)90086-8

Chang, P-C., Wang, Y-W., \& Liu, C-H. 2007. The development of a weighted evolving fuzzy neural network for PCB sales forecasting. Expert Systems with Applications 32: 86-96.

Fajar, M., Prasetyo, O.R., Nonalisa, S., Wahyudi. 2020. Forecasting unemployment rate in the time of covid-19 pandemic using google trends data (case of Indonesia). International Journal of Scientific Research in Multidisciplinary Studies, Vol.6, Issue.11, pp.29-33, 2020.

Huang, M.Y., Rojas, R.R., Convery, P.D. 2019. Forecasting stock market movements using Google Trend searches. Empirical Economics. DOI: https://doi.org/10.1007/s00181-019-01725-1

Woo, J., Owen, A.L. 2019. Forecasting private consumption with Google Trends data. Journal of Forecasting,38, pp. 81-91. DOI: https://doi.org/10.1002/for.2559 